(RESEARCH ARTICLE)

\title{
Effective microorganisms for the cultivation and qualitative improvement of onion (Allium cepa L.)
}

\section{Prisa Domenico *}

CREA Research Centre for Vegetable and Ornamental Crops, Council for Agricultural Research and Economics, Via dei Fiori 8, 51012 Pescia, PT, Italy.

Publication history: Received on 01 July 2019; revised on 15 July 2019; accepted on 19 July 2019

Article DOI: https://doi.org/10.30574/wjarr.2019.2.3.0038

\begin{abstract}
The aim of the study was to investigate how effective microorganisms (EM) affect the quality and growth of onions cvs "Dorata di Bologna", "Lunga di Firenze", "Bianca Musona", "Rossa di Tropea". An experiment was carried out with 2 treatments: 1) soil inoculated with EM microorganisms; 2) soil without EM microorganisms (control). The test showed a significant increase in the agronomic parameters analysed in the plants treated with Effective microorganisms. In fact, all the onions of the different varieties, treated with EM microorganisms, showed a significant increase in bulbs weight, bulbs diameter, bulbs length and root weight. There is also an increase in radical growth in the theses with Effective Microorganisms, an aspect confirmed in other experiments in vegetable and ornamental crops. Increased root growth results in improved resistance to water and transplant stress and a higher supply of nutrients to the plant, which consequently grows better. It is therefore clear from the evidence that the use of this selection of microorganisms, inoculated into the soil, can significantly improve the quality of onions bulbs.
\end{abstract}

Keywords: Effective microorganisms (EM); Plant quality; Rhizobacteria; Horticulture; Vegetable plants; Soil improvement

\section{Introduction}

Effective microorganisms are a commercial microbial selection containing a mixture of coexisting beneficial microorganisms collected from the natural environment.

This selection was developed at the University of Ryukyus, Japan, in early 1980 by Prof. Dr. Terou Higa. About 80 different microorganisms are able to positively influence the decomposing organic substance in such a way as to transform it into a process of "promoting life".

The main species involved in EM include [1-2]:

- Lactic acid bacteria - Lactobacillus plantarum, L. casei, Streptoccus lactis;

- Photosynthetic bacteria - Rhodopseudomonas palustrus, Rhodobacter spaeroides [3];

- Yeast - Saccharomyces cereviasiae, Candida utilis;

- Actinomycetes - Streptomyces albus, S. griseus;

- Fermenting fungi - Aspergillus oryzae, Mucor hiemalis.

EM is a fermented mixed culture of naturally occurring species of microorganisms coexisting in an acid environment ( $\mathrm{pH}$ less than 3.5). Microorganisms in EM improve crop health and yield by increasing photosynthesis, producing bioactive substances such as hormones and enzymes, accelerating the decomposition of organic materials and controlling soil diseases. Effective microorganisms can be used as herbal insecticides to control insects and pathogenic

\footnotetext{
${ }^{*}$ Corresponding author

E-mail address: domenico.prisa@crea.gov.it
} 
microorganisms and can also be used as plant growth inducers. Soil microorganisms have an important influence on soil fertility and plant health. EMs interact with the soil-plant ecosystem by controlling plant pathogens and disease agents, solubilising minerals, increasing plant energy availability, stimulating the photosynthetic system, maintaining the microbiological balance of the soil, fixing biological nitrogen [4]. A characteristic of this mixture is the coexistence of aerobic and anaerobic micro-organisms. After Higa's research in Japan [1], the characteristics of EM have been studied in many countries. Studies have shown positive effects of the application of EM on soils and plants on soil quality and nutrient supply [5], plant growth [6], crop yield [7], [5] and crop quality [8-11]. However, in some studies no positive effects were found [4], [12-13].

This study has tested the possible use of EM microorganisms in the cultivation and improvement of the quality of onion (Allium cepa L.), to increase knowledge and improve the protocols of use of this microbial selection applied in various fields of agriculture around the world.

\section{Material and methods}

\subsection{Greenhouse experiment and growing conditions}

The experiments began in early November 2018 (mean temperature $7.5^{\circ} \mathrm{C}$ ), were carried out price experimental greenhouses of the CREA-OF of Pescia (Pt), Tuscany, Italy $\left(43^{\circ} 54^{\prime} \mathrm{N} 10^{\circ} 41^{\prime} \mathrm{E}\right.$ ) on bulbs of onion (cvs "Dorata di Bologna”, "Lunga di Firenze”, “Bianca Musona”, "Rossa di Tropea”). The bulbs were placed in pots $\varnothing 14 \mathrm{~cm} ; 40$ bulbs for thesis divided into replicas of 20 bulbs each, for all types of onion.

All bulbs were fed with the same amount of nutrients supplied through controlled release fertilizer $(5 \mathrm{~kg} \mathrm{~m}-3 \mathrm{of}$ Osmocote Pro® 3 - 4 months containing 190 g/kg N, 39 g/kg P, 83 g/kg K) blended with the growing medium before transplant.

The 2 experimental theses in cultivation were:

Thesis without EM (CTRL), with only water.

Thesis with (EM) with activated in dilution 1:100 (2L of 1:100 dilution inoculum was used with EM for every 10L of peat, same proportion for the control thesis where only water was used);

The lighting of the greenhouse at the plant level was about 12,000 lux with high pressure sodium lamps. The plants were lit for 16 hours a day. A minimum daytime temperature of $20^{\circ} \mathrm{C}$ and a night-time temperature of $18{ }^{\circ} \mathrm{C}$ were maintained in the greenhouse. On the 6th of June, bulbs weight, diameter (for all cvs) and length (only for cv "Lunga di Firenze") were recorded.

\subsection{Statistics}

The experiment was carried out in a randomized complete block design. Collected data were analysed by one-way ANOVA, using GLM univariate procedure, to assess significant $(P \leq 0.05,0.01$ and 0.001$)$ differences among treatments. Mean values were then separated by LSD multiple-range test $(P=0.05)$. Statistics and graphics were supported by the programs Costat (version 6.451) and Excel (Office 2010).

\section{Results}

\subsection{Plant growth}

The test showed a significant increase in the agronomic parameters analysed in the plants treated with Effective Microorganisms. In fact, all the onions of the different varieties, treated with EM microorganisms, showed a significant increase in bulb weight, bulb diameter, bulb length (only for cv "Lunga di Firenze") and root weight.

In "Dorata di Bologna", the diameter of the bulb was $36.36 \mathrm{~mm}$ in the EM thesis, against $27.69 \mathrm{~mm}$ of the control (Fig.1A), $49.13 \mathrm{~g}$ in the EM thesis, against $22.87 \mathrm{~g}$ of the control with regard to the weight of the bulb (Fig.1B). There is also an increase in root weight, $17.11 \mathrm{~g}$ in EM compared to $12.33 \mathrm{~g}$ in control (Fig. 1C, 5A). 

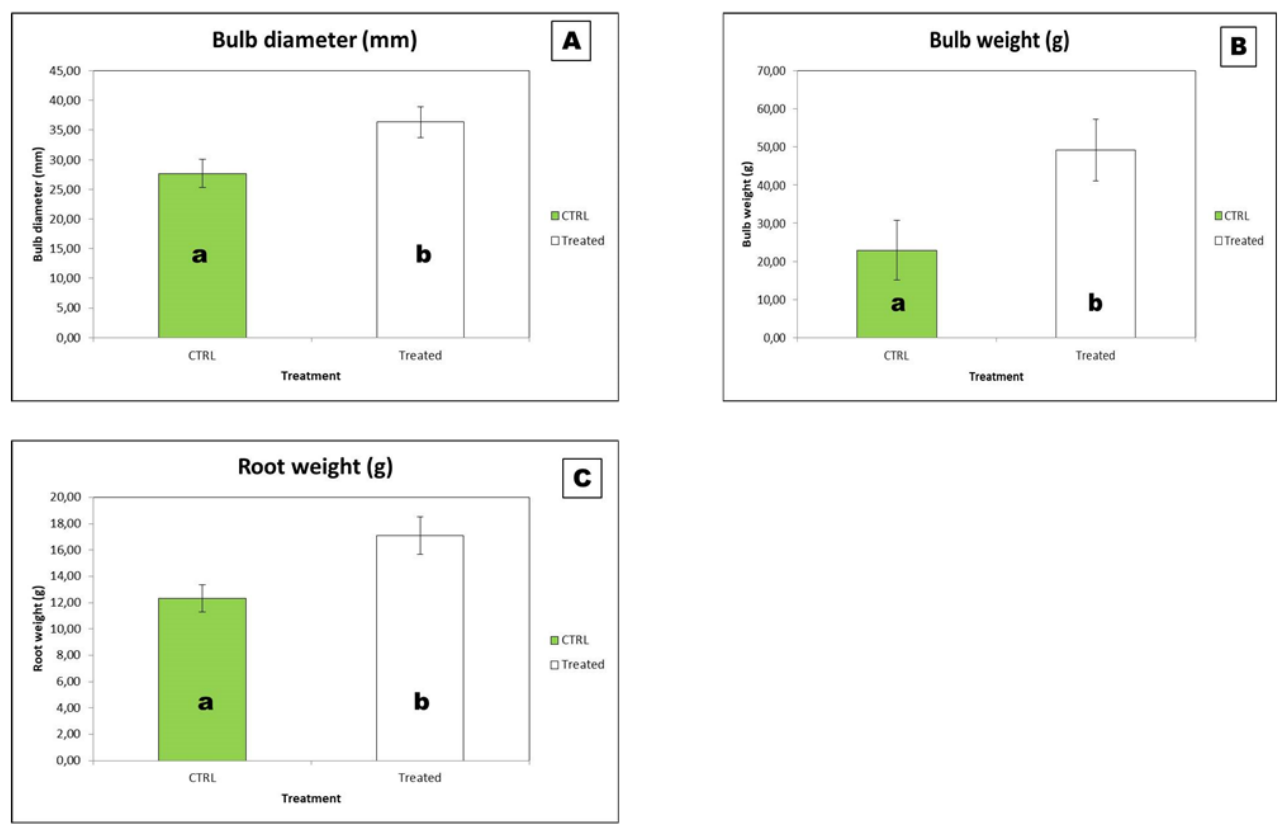

Figure 1 Effect of Effective Microorganisms (EM) on the growth of onion cv "Dorata di Bologna". Each value reported in the graph is the mean of three replicates \pm standard deviation. Statistical analysis performed through one-way ANOVA. Different letters for the same parameter indicate significant differences according toLSD test $(\mathrm{P}=0.05)$.
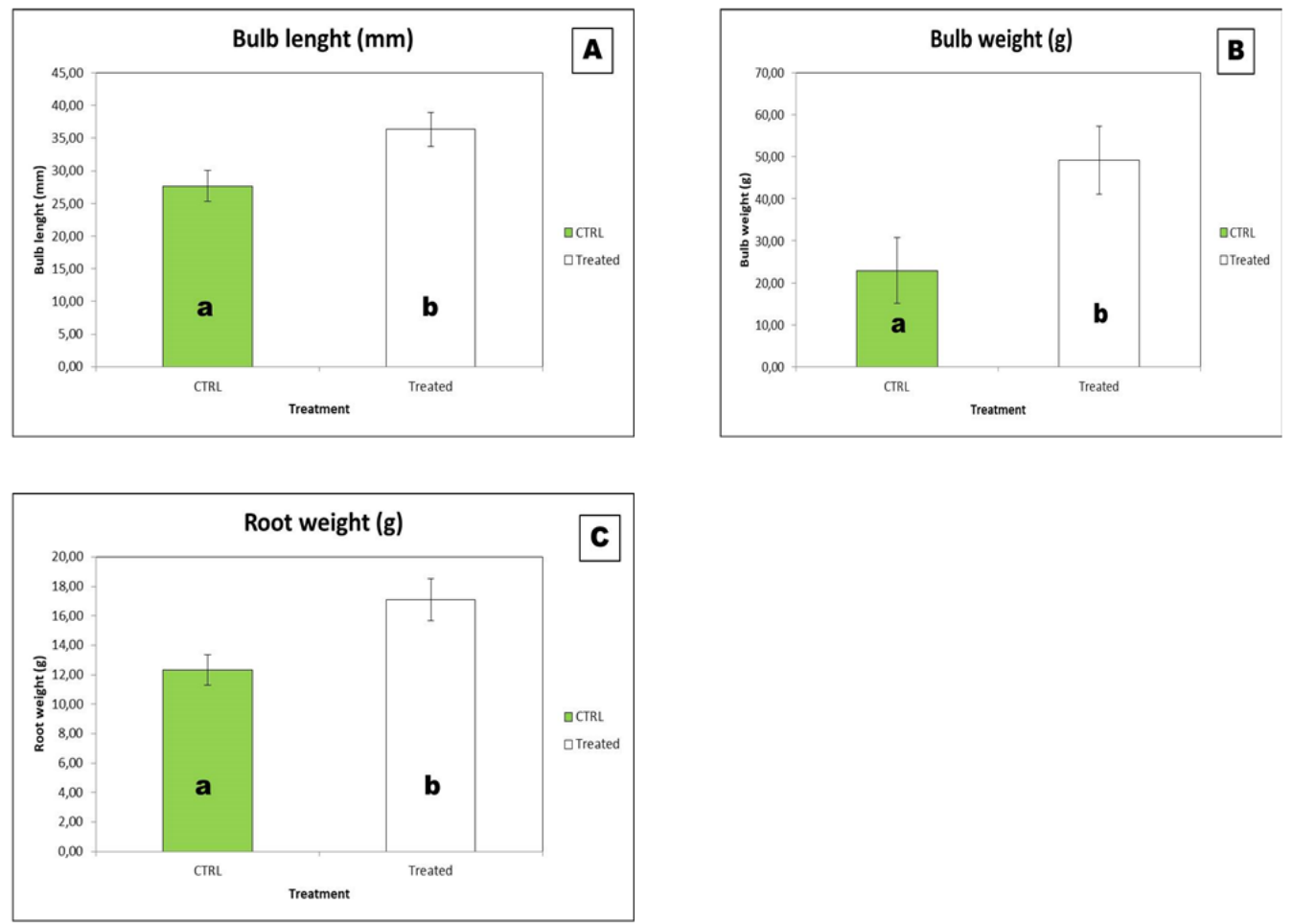

Figure 2 Effect of Effective Microorganisms (EM) on the growth of onion cv "Lunga di Firenze". Each value reported in the graph is the mean of three replicates \pm standard deviation. Statistical analysis performed through one-way ANOVA. Different letters for the same parameter indicate significant differences according to LSD test $(\mathrm{P}=0.05)$. 
In "Lunga di Firenze", the length of the bulbs increased, $96.60 \mathrm{~mm}$ in EM, compared to $80.81 \mathrm{~mm}$ for the control (Fig. 2A). There is an increase in the weight of the treated bulbs, $32.55 \mathrm{~g}$ against $16.92 \mathrm{~g}$ of the untreated control (Fig. 2B). In addition, there is an increase in radical weight, $58.66 \mathrm{~g}$ in the EM-treated thesis, compared to $37.11 \mathrm{~g}$ in the untreated control (Fig. 2C, 5B).

In "Bianca Musona", the data show a significant increase in the diameter of the bulb, $36.81 \mathrm{~mm}$ in EM, compared to $20.25 \mathrm{~mm}$ in the control (Fig.3A). There is also a significant increase in the weight of the bulbs, $42.71 \mathrm{~g}$ in EM compared to $17.46 \mathrm{~g}$ in the untreated control (Fig.3B). The data also show a significant increase in radical weight, $37.56 \mathrm{~g}$ in EM compared to $28.66 \mathrm{~g}$ in untreated control (Fig.3C, 5C).
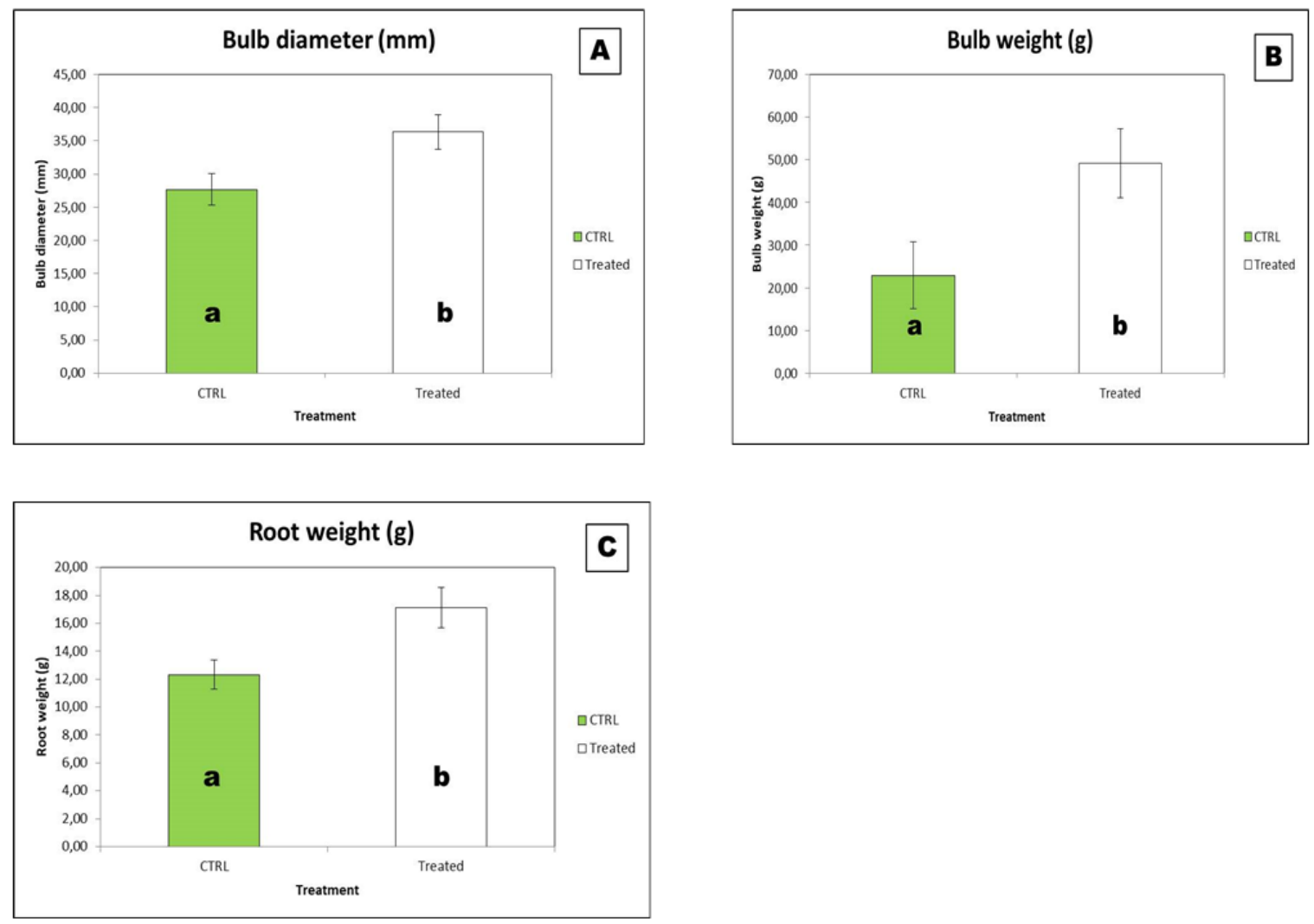

Figure 3 Effect of Effective Microorganisms (EM) on the growth of onion cv "Bianca Musona". Each value reported in the graph is the mean of three replicates \pm standard deviation. Statistical analysis performed through one-way ANOVA. Different letters for the same parameter indicate significant differences according to LSD test $(P=0.05)$.

In "Rossa di Tropea" the data show a significant increase in the diameter of the bulb, $38.55 \mathrm{~mm}$ in Em compared to $24.22 \mathrm{~mm}$ of the control (Fig .4A). In addition, there was a significant increase in the weight of the bulb, $50.11 \mathrm{~g}$ in EM compared with $21.39 \mathrm{~g}$ in the control (Fig.4B). The test also showed, as for the other onion varieties, a significant increase in root weight, $28.99 \mathrm{~g}$ in EM compared to $23.44 \mathrm{~g}$ in the untreated control (Fig. 4C, 5D). 

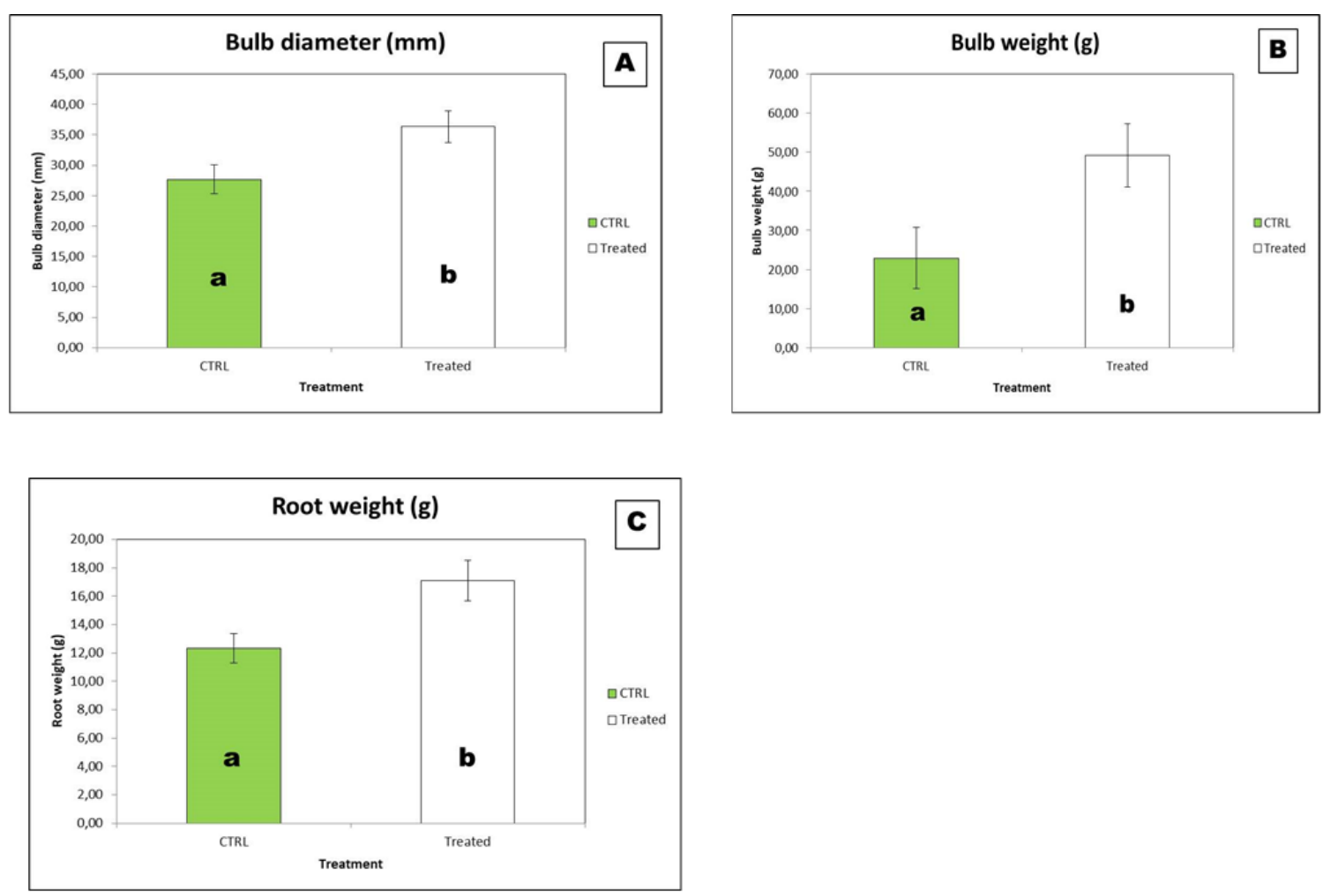

Figure 4 Effect of Effective Microorganisms (EM) on the growth of onion cv "Rossa di Tropea”. Each value reported in the graph is the mean of three replicates \pm standard deviation. Statistical analysis performed through one-way ANOVA. Different letters for the same parameter indicate significant differences according to LSD test $(P=0.05)$.
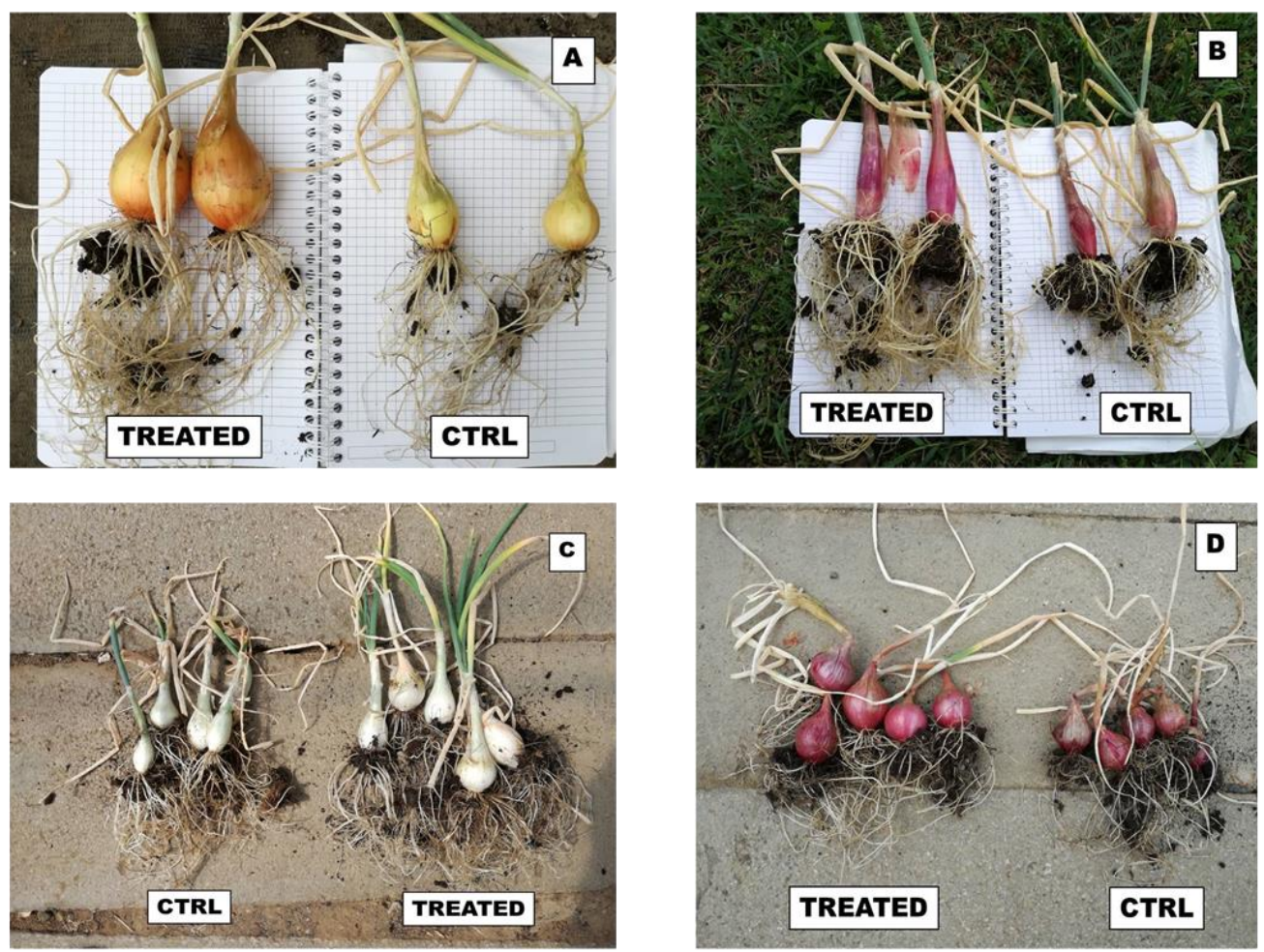

Figure 5 Comparison of onions treated with Effective microorganisms and control, cvs "Dorata di Bologna” (A), "Lunga di Firenze" (B), "Bianca Musona" (C), "Rossa di Tropea” (D). 


\section{Discussion}

The literature does not reveal studies on the effects of Effective Microorganisms on the quality of onion plants, although several works show the effects of this microbial selection on horticultural, ornamental and fruit crops [14][15].

In this trial all varieties of onions treated with EM microorganisms showed a significant increase in diameter, weight and length of bulbs and root weight.

EM microorganisms stimulate onion bulbs already at the time of transplantation because they guarantee a better water supply and an increase in the solubilization of minerals present in the substrate and in the soil, in particular Ca, $\mathrm{P}$ and Mg. Ca influences many beneficial processes for the plant: a high content of Ca leads to fewer diseases, reduction of insect attack, better preservation of the product [4]. The results show a faster growth rate of EM-treated onion bulbs and a reduction in the possible development of diseases.

Scientists have shown that Effective Microorganisms can increase fruit weight, yield and photosynthesis [16]. EM applied with green manure significantly increased tomato yields, which in the third year of cultivation were comparable to those obtained with chemical fertilizers [17].

There is also an increase in radical growth in the theses with Effective Microorganisms, an aspect confirmed in other experiments in vegetable and ornamental crops [18][19]. Increased root development results in increased resistance to water and transplant stress [20] and a higher supply of nutrients to the plant, which consequently grows better.

\section{Conclusion}

The test showed how the use of Effective Microorganisms can improve the quality of the onion bulbs cvs "Dorata di Bologna", "Lunga di Firenze", "Bianca Musona", "Rossa di Tropea", in particular by significantly increasing the diameter, weight, length of the bulbs and root weight. EM microorganisms can have a positive effect on the absorption of other minerals, particularly calcium, by promoting plant growth, improving product quality, growth rate and resistance to biotic and abiotic stress.

\section{Compliance with ethical standards}

\section{Acknowledgments}

The article is part of the "Micronaturale" project: alternative techniques to synthetic chemistry for the cultivation and defence of plants

\section{Disclosure of conflict of interest}

Disclosure of conflict of interest none to declare.

\section{References}

[1] Higa T. (1991). Soil environment and microorganisms, and the health of crops. Report by the International Nature Farming Research Center, Atami, Japan. 133.

[2] Daly MJ and Stewart DPC. (1999). Influence of "Effective Microorganisms" (EM) on Vegetable Production and Carbon Mineralization-A Preliminary Investigation, Journal of Sustainable Agriculture, 14, 2-3, 15-25.

[3] Condor AF, Gonzalez P, and Lakre C. (2007). Effective microorganisms: myth or reality? The Peruvian Journal Biology, 14, 315-319.

[4] Olle M. (2013). Effect of efficient microorganisms on yield, quality and preservation of vegetables. In: Gardening Forum, 2013, 10-13.

[5] Xu HL, Wang R and Miridha Mau. (2001). Effects of Organic Fertilizers and a Microbial Inoculant on Leaf Photosynthesis and fruit Yield and Quality of Tomato plants. Journal of Crop production, 3, 173-182. 
[6] Prisa D. (2019). Effect of chabazitic-zeolites and effective microorganisms on growth and chemical composition of Aloe barbadensis Miller and Aloe arborescens Miller. International Journal of Agricultural Research, Sustainability, and Food Sufficiency, 6(01), 315-321.

[7] Escano CR. (1996). Experiences on EM technology in the Philippines.

[8] Ncube L, Minkeni PNS and Brutsch 0. (2011). Agronomic suitability of effective micro-organisms for tomato production. African Journal of Agricultural research, 6, 650-654.

[9] Ncube L and Calistus B. (2012). Effects of the integrated use of effective microorganisms, compost and mineral fertilizer on greenhouse-grown tomato. African Journal of plant Science.

[10] Prisa D. (2019). Effective microorganisms and chabazitic-zeolites for the improvement quality of Echinopsis Hybrids. Asian Academic Research Journal of Multidisciplinary. 6(2), 23-34.

[11] Formowitz B, Elango F, Okumoto S, Müller T and Buerkert A. (2007). The role of effective microorganisms in the composting of banana (Musa ssp.) residues. J. Plant Nutr. Soil Sci., 170, 649-656.

[12] Mayer J, Scheida S, Widmera F, Fließbachb A and Oberholzer HR. (2010). How effective are 'Effective microorganisms ${ }^{\circledR}(E M)$ '? Results from a field study intemperate climate. Appl. Soil Ecol.

[13] Schweinsberg MS and Torsten, M. (2009). Impact of effective microorganisms and other biofertilizers on soil microbial characteristics, organic-matter decomposition, and plant growth. Journal of Plant Nutrition and Soil Science, 172(5), $704-712$.

[14] Prisa, D. (2019). Improvement quality and content of pepper and chilli nitrates influenced by the effective microorganisms. American Scientific Research Journal for Engineering, Technology, and Sciences (ASRJETS) 53(1), 176-181.

[15] Prisa D. (2019). Improvement quality of aubergine plants with effective microorganisms. Asian Academic Research Journal of Multidisciplinary. 6(3), 1-8.

[16] Idris II, Yousif MT, Elkashif ME and Bakara FM. (2008). Response of tomato (Lycopersicum esculentum Mill.) to application of effective microorganisms. Gezira journal of Agricultural Science, 6(1), North America, 6, oct.2012.

[17] Marambe B and Sangakkara UR. (1996). Effect of EM on weed populations, weed growth and tomato production inkyusei nature farming. http://www.futuretechtoday.net/em/index2.htm (pdf) effective microorganisms and their influence on vegetable production - a review.

[18] Siquera MFB, Sudrè CP, Almeida LH, Pegorerl APR and Akiba F. (2012). Influence of Effective Microorganisms on seed Germination and plantlet vigor of selected crops.

[19] Zaenudin, S. (1993). Effective Microorganisms (EM4) Technology in Indonesia.

[20] Prisa D. (2019). Rhizobacteria and zeolites for overcoming saline stress in the cultivation of succulent plants. The International Journal of Engineering and Science (IJES), 8(5).

\section{How to cite this article}

Prisa D. (2019). Effective microorganisms for the cultivation and qualitative improvement of onion (Allium cepa L.) World Journal of Advanced Research and Reviews, 2(3), 01-07. 